\title{
DIGITALIZATION OF ADMINISTRATIVE PROCESS IN THE GERMAN HEALTHCARE SYSTEM WITH THE FOCUS ON DENTAL PRACTICES
}

\author{
Karolin Bosch, Linda Mosenthin and Christian Schieder \\ Technical University of Applied Sciences Amberg-Weiden \\ Hetzenrichter Weg 15, 92637 Weiden, Germany
}

\begin{abstract}
The digitization of processes in healthcare offers the opportunity to reduce costs and at the same time increase the quality of treatment. A large number of studies show how digitization can optimize and automate processes in healthcare. However, no study has yet addressed the specific requirements of processes digitalization in dental practices. This paper examines the status quo and opportunities of process digitization for dental practices in the German healthcare system. A structured literature review was used to identify 25 previous relevant papers. Their categorization and analysis revealed existing research gaps, which were explored in detail based on semi-structured in-depth interviews with four dentists. The analysis shows that most organizations are at an early stage of digital transformation, but are actively working to improve the digitization of their processes.

Our findings provide a detailed description of the current challenges and starting points for process digitization and optimization in dentistry. They serve as a basis for further development and help to improve the quality and efficiency of processes in healthcare.
\end{abstract}

\section{KEYWORDS}

German Healthcare System, Dental Practice, Administrative Processes, Business Process Management, Business Process Automation, Process Digitalization

\section{INTRODUCTION}

Healthcare systems are facing a variety of challenges. The aging society and the increase in chronic diseases, even at a young age, pose major challenges for medical care. It must be provided in the best possible way under limited financial and human resources. Modern technology can help here. In addition to devices in diagnostics and treatment, technology can support the optimization of processes (Marsilio \& Prenestini, 2020). To deal with this contradiction of efficiency and quality, process orientation has become increasingly important in recent years. Every healthcare organization should work in a process-oriented manner and align itself accordingly. On this basis, the targeted use of IT can enable the best possible design of processes from a cost and efficiency perspective. Therefore, dental practices are also challenged to become more process-oriented and digital. In order to get an overview of the current state of research on the subject, we conducted a structured literature review at the beginning of our work. This showed that some studies have already looked at the control and automation of processes in the health care sector. However, there are no studies on process management and process digitization in the dental field in the German healthcare system (de Koning et al., 2006; De Ramón Fernández et al., 2019; Mens et al., 2015; Müller \& Rogge-Solti, 2011; Rolón et al., 2015). This study aims to close this gap and therefore examines the status quo of process digitization in dental practices. Semi-structured interviews were used to analyze the current perception and situation of different dental practices in the German healthcare system.

The remainder of this paper is organized as follows: Section 2 describes the methodology of the study, Section 3 briefly summarizes the related structured literature review and Section 4 provides insight into the theoretical background of the German healthcare system. The results are presented and discussed in Section 5 before we conclude the paper in Section 6 by highlighting the limitations of our research and providing an outlook for future work. 


\section{METHODICAL APPROACH}

This section explains the methodological procedure in detail: For a focused research, we conducted a structured literature review at the beginning. Since no relevant work on process management and digitization in the German healthcare system was found, expert interviews with dental practices followed. These interviews were semi-structured and based on an interview guideline that was adapted to the respective expert group. The interview questions resulted from the research gaps identified in the literature review. Each interview was scheduled for one hour and was conducted online via video or telephone. The aim was to clearly define the administrative processes in dental practices and their interfaces, as well as the opportunities for optimization and automation through digitization. In order to obtain all the necessary information, the interview guideline was structured accordingly. The first step was to understand the role and task of the interviewee and his organization. Furthermore, all administrative processes in the organization as well as the interfaces between the dentists and all interfaces involved were to be recorded. In addition to the administrative processes, the aim was also to clarify the individual requirements of the participants. To this end, personal requirements for work and process optimization, the current status of digitization, the possibilities and opportunities of digitization, and personal attitudes toward digitization were asked (Barriball \& While, 1994; Flick et al., 2004; McIntosh \& Morse, 2015). When selecting the participants, care was taken to ensure that the individuals already had experience with the topic of digitization in the dental field or had already dealt with it. In the search for participating in dental practices, over 200 practices were contacted, most of which practice in the state of Bavaria. A total of four interviews (three female; one male interviewee) were conducted in the dental field. Three of the interviewees are practicing dentists, two of whom have a managerial position in a practice and are self-employed. The fourth person was a dental administrative assistant who gave us insights into her daily work.

\section{STRUCTURED LITERATURE REVIEW FOR ANALYZING THE RESEARCH STATUS}

As a basis for the research work, a structured literature review was conducted on the topic of process management in healthcare. The focus of the structured literature review was to provide a neutral overview of the topic by integrating different research findings and identifying the relevant research gaps to be addressed subsequently. In order to collect all relevant literature, the procedure followed the guidelines of a systematic literature review according to (Vom Brocke et al., 2009). To achieve the most comprehensive result possible, eleven of the most important databases for information systems served as the basis for the research. The following search string was defined: (Business Process* OR Workflow Management OR Process Management) AND (Healthcare).

Subsequently, all eleven databases were searched with the search string and additionally filtered by abstract, keywords, and title. Due to the high sum of papers found and the desired accuracy, the focus was placed on all results with the search string in the title. For further analysis, only papers published between 2015 and May 2020 and written in English were considered. In addition, only articles from peer-reviewed scientific journals and conferences were used to ensure high scientific standards. All results that did not meet the inclusion criteria were filtered out.

After this step, a subtotal of 363 results remained. These articles were manually evaluated by title, keywords, and abstract. The evaluation aimed to find articles suitable for the research topic. With this selection, we conducted a forward and backward search and determined the final corpus of articles (25 results).

The next step was to classify the results following Webster and Watson (Webster \& Watson, 2002). The 25 papers on process management in healthcare were categorized according to the most frequently cited approaches to process management, such as business process management (BPM) in general, business process modeling (BPMod), business process improvement (BPI), and business process re-engineering (BPR). Additionally, they were clustered according to their application level. That is, whether the respective method was applied in a specific process, a department, or an entire organization, or even along with several organizations and their interfaces. 
Table 1. Classification of previous research paper

\begin{tabular}{|c|c|c|c|c|c|c|c|c|}
\hline \multirow[t]{3}{*}{ Citationı } & \multirow[t]{3}{*}{ Methodology } & \multicolumn{7}{|c|}{ Process orientation } \\
\hline & & \multicolumn{4}{|c|}{ Process management } & \multicolumn{3}{|c|}{ Application level } \\
\hline & & $B P M$ & $\begin{array}{c}B P \\
M o d\end{array}$ & $B P I$ & $B P R$ & $\begin{array}{l}\text { System/ } \\
\text { sector }\end{array}$ & $\begin{array}{l}\text { Organi- } \\
\text { zation }\end{array}$ & Unit \\
\hline (Ahmed et al., 2019) & literature review & & & $\mathrm{x}$ & & $\mathrm{x}$ & & \\
\hline (Andreasson et al., 2016) & grounded theory & $\mathrm{x}$ & $\mathrm{x}$ & & & & $\mathrm{x}$ & $x$ \\
\hline (Baldassarre \& Ricciardi, 2016) & case study & $\mathrm{x}$ & & & & & $\mathrm{x}$ & $\mathrm{x}$ \\
\hline (Buttigieg et al., 2016) & literature review & $\mathrm{x}$ & & & & $\mathrm{x}$ & & \\
\hline (Cherni et al., 2019) & framework & & & & $\mathrm{x}$ & $\mathrm{x}$ & & \\
\hline (de Koning et al., 2006) & case study & $\mathrm{x}$ & & & & & $\mathrm{x}$ & \\
\hline (De Mast et al., 2011) & framework & & & $\mathrm{x}$ & & & $\mathrm{x}$ & \\
\hline (De Ramón Fernández et al., 201 & literature review & $\mathrm{x}$ & & & & & $\mathrm{x}$ & \\
\hline (El Hadj Amor \& Ghannouchi, 2 ) & case study & $\mathrm{x}$ & & & & & $\mathrm{x}$ & \\
\hline (Fältholm \& Jansson, 2008) & case study & $\mathrm{x}$ & & & & & $\mathrm{x}$ & \\
\hline (Goreva et al., n.d.) & survey & $\mathrm{x}$ & & & & $\mathrm{x}$ & & \\
\hline (Hellström et al., 2010) & case study & $\mathrm{x}$ & & & & & $\mathrm{x}$ & \\
\hline (Ilahi et al., 2014) & framework & $\mathrm{x}$ & & & & & & $\mathrm{x}$ \\
\hline (Khodambashi, 2013) & literature review & & & & $\mathrm{x}$ & & $\mathrm{x}$ & \\
\hline (Lenz \& Reichert, 2007) & none & $\mathrm{x}$ & & & & & $\mathrm{x}$ & \\
\hline (Liu et al., 2017) & framework & & $\mathrm{x}$ & & & & $\mathrm{x}$ & \\
\hline (Martinho et al., 2015) & case study & $\mathrm{x}$ & $\mathrm{x}$ & & & & & $\mathrm{x}$ \\
\hline (Mens et al., 2015) & case study & $\mathrm{x}$ & & & & & $\mathrm{x}$ & \\
\hline (Müller \& Rogge-Solti, 2011) & proposal & & $\mathrm{x}$ & & & & $\mathrm{x}$ & \\
\hline (Plsek, 1997) & theoretical & & & $\mathrm{x}$ & & & $\mathrm{x}$ & \\
\hline (Reichert, 2011) & none & $\mathrm{x}$ & & & & & $\mathrm{x}$ & \\
\hline (Rolón et al., 2015) & case study & & $\mathrm{x}$ & & & & $\mathrm{x}$ & \\
\hline (Ruiz et al., 2012) & theoretical & & $\mathrm{x}$ & & & & $\mathrm{x}$ & \\
\hline (Stephenson \& Bandara, 2007) & action research & & $\mathrm{x}$ & & & & $\mathrm{x}$ & $\mathrm{x}$ \\
\hline (Vest \& Gamm, 2009) & literature review & $\mathrm{x}$ & & & & $\mathrm{x}$ & & \\
\hline
\end{tabular}

The following summarizes the findings from the structured literature review. The research devoted most application and attention to process management in hospitals. Processes within or between other types of healthcare organizations were not examined in the papers. The rationale for this is that process management is easier to implement in a specific unit than in a collaborative and complex system with different units (Andreasson et al., 2016; Hellström et al., 2010). In addition, process analysis and improvement focused on medical treatment rather than administrative processes. Measuring internal and external metrics or more real-world experimentation with new processes could lead to more comprehensive and detailed insights into the impact of process management in healthcare systems (Cherni et al., 2019; De Ramón Fernández et al., 2019; El Hadj Amor \& Ghannouchi, 2017). Similarly, rigid planning of processes in healthcare is not productive because treatment must be different for each patient and standards are constantly evolving. The targeted use of novel technology could be the solution for flexibility and sustainability in the management of processes. Therefore, the definition of processes must be done first before implementing the appropriate IT (De Ramón Fernández et al., 2019; Lenz \& Reichert, 2007; Reichert, 2011). Consequently, the digitization of processes in healthcare offers multiple potentials to optimize defined processes. There are research gaps in the application of process management and process digitization in various healthcare facilities outside the hospital. This paper, therefore, focuses on the current status and opportunities for the digitization of administrative processes in dental practices and their interfaces in the German healthcare system. 


\section{THEORETICAL STRUCTURE OF THE GERMAN HEALTHCARE SYSTEM IN RELATION TO DENTISTS.}

In Germany, the healthcare system is part of the social insurance system. It is a federal system with a division of tasks and competencies at the national and state levels. All the different actors, institutions, and levels shape the complexity of the healthcare system in Germany. The state sets the framework conditions through laws and monitors compliance with them. Medical care is ensured by the self-administration of the most important players (associations for health insurances, hospitals, physicians and dentists). At the federal level, the Federal Joint Committee (G-BA) regulates all framework conditions for medical care within the framework of the laws and state supervision. At the state level, the government and associations are responsible for the regional organization of medical care (Aufgaben Und Organisation Der GKV|BMG, 2018; Gesundheitswesen in Deutschland, n.d.; Maier \& Juschkat, 2020).

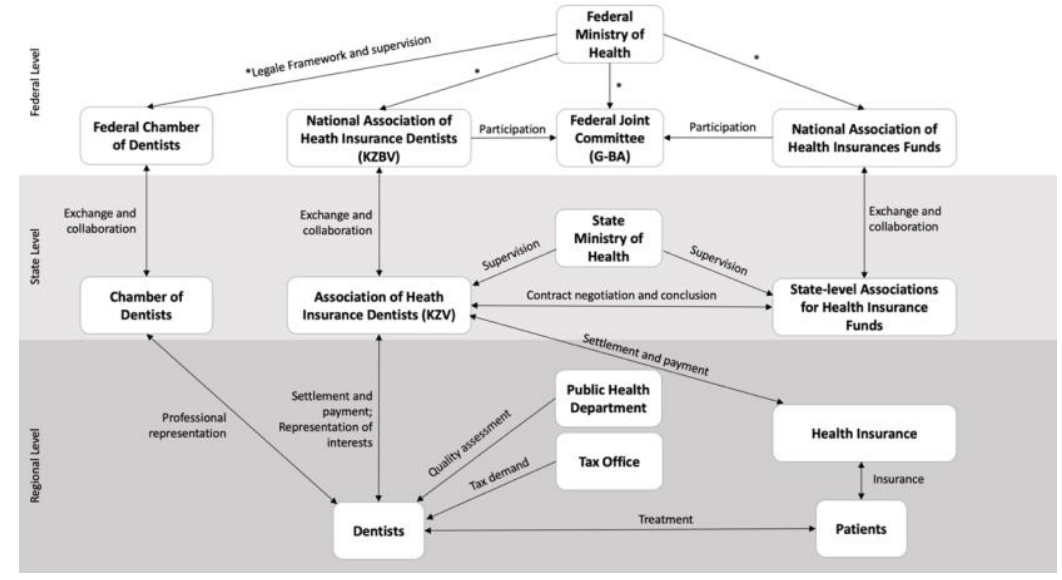

Figure 1. Sociogram of the organizations in the German healthcare in relation to dentists

Dentists are responsible for the prevention, treatment, and follow-up of teeth, jaws, and gums (Was Macht Ein Angestellter Zahnarzt?, 2018). The Kassenzahnärztliche Bundesvereinigung (KZBV) represents the interests of all dentists participating in contractual dental care in the treatment of patients with statutory health insurance (KZBV - Kassenzahnärztliche Bundesvereinigung - Startseite, n.d.). Besides, the Dental Association is the professional association of dentists (Startseite: Bundeszahnärztekammer Arbeitsgemeinschaft Der Deutschen Zahnärztekammern e.V. (BZ̈̈K), n.d.). Both organizations are represented at the federal and state level. Figure 1 illustrates the sociogram of the various organizations in the German healthcare system in relation to dentists.

The basis for the digitization of the German healthcare system is the telematics infrastructure (TI). As a digital platform, it connects all organizations in the statutory health insurance system. Within the framework of the TI, patient information can be exchanged securely across the various sectors. The patient has control over his or her data and determines which applications are activated and who receives which data. Connection to the TI is mandatory for all healthcare providers, including dentists. For patients, on the other hand, participation is voluntary (E-Health - Digitalisierung Im Gesundheitswesen, 2020; Telematikinfrastruktur, n.d.).

\section{RESULTS OF THE DEPTH-INTERVIEWS}

This section explains and discusses the results of the conducted interviews. On average, the group of interviewees had 19.5 years of professional experience. This testifies a deep and large knowledge background. Concerning digitization, it is evident that the respondents find digitization helpful in their everyday lives, on a Likert scale of 1 to 10. They use digital technology in their everyday life outside the practices and enjoy learning about and trying out new products. In contrast to their everyday lives, however, the reality of the interview participants in the practices looks different. Here, the assessment of the degree of digitization is only just above half (on a Likert scale, 7.25 out of 10). Digitalization is already there, but its possibilities are far from exhausted. 
Looking at the interfaces of dental practices with the German healthcare system, these are perceived as good by the respondents (on a Likert scale 7.75 out of 10). According to the information provided, the most important interfaces include the various health insurance companies, external laboratories and the KZV. Tax consultants, the tax office and the health office were listed among the general interfaces.

The current status of process digitization depends on various factors. These factors are the expertise of the staff, process orientation as a management task, the existing IT infrastructure, and the interfaces to other organizations in healthcare or in general. These factors in turn influence each other. The factors and their dependencies are shown in a graphic.

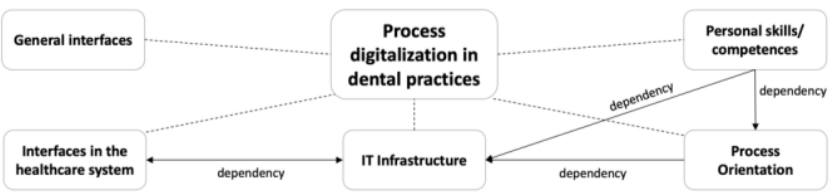

Figure 2. Influence factors of prozess digitalization below.

The status quo and possible optimization potentials of the influencing factors are presented individually

\section{Personal competences}

Among the interviewed persons and the staff in the practices, few competencies in process orientation, process management, and digitization are existent. Because of this gap, targeted digitization is a major challenge. The individual practices have to master the digital transformation with the given workforce and without prior knowledge. Therefore, this transformation is a major hurdle and challenge for the individual organization. Also, setting up, optimizing, and digitizing processes is more difficult when there is little knowledge in process management.

Possible starting points are the further training of staff in process management and the targeted digitization of a practice. Partnership-based collaboration and exchange between individual practices on digitization could build up and disseminate the necessary knowledge. Collaborative networks for the digitalization of practices could provide additional knowledge, guidance, and exchange of experience. Another possibility is for long-established associations or state government policies to install experts to serve as advisors.

Future work could analyze the various possibilities and develop a possible concept for professional competence enhancement. As already mentioned, existing expertise affects how process management is conducted. Consequently, personnel competence can be regarded as the basis for process management.

Process management

Despite the low application of process management, five different processes can be defined as areas in the administrative work of dental practices. Scheduling appointments with patients is one of them, as are materials planning, accounting, quality management and personnel management.

Appointments are made by telephone. Digitization and automation of appointment scheduling is not considered possible, as too many parameters have to be taken into account in the targeted scheduling of appointments by trained employees. Material planning is currently done in a hybrid format. As inventory becomes more depleted, order cards are collected manually and orders are placed digitally by the responsible personnel. Accounting is done manually through the tax office. The two processes could thus be fully digitized and automated. Personnel management is partially digitized, depending on the software used. The health department's specifications and guidelines for quality management are made available digitally.

One solution and topic area for future work may be the use of artificial intelligence in making appointments or intelligent help in managing material inventories.

\section{IT infrastructure}

There are already initial software solutions that facilitate the daily work in a dental practice and patient education. DAMPSOFT and synMedico should be mentioned here. DAMPSOFT offers a specialized software solution for the billing system required in dental practices and for the entire practice management. This is a modular software system in which the functions can be put together individually. synMedico focuses on patient education and accurate information about the costs incurred for the customer. Both software solutions would be of great advantage for the daily work of any dental practice, but the introduction of such software is fraught with challenges. Apart from the high costs that a dental practice has to incur for the introduction, there is a lack of trained personnel who can both a lack of trained personnel who can manage both the target-oriented implementation and the handling of the new. Also, end-to-end software support often requires practices to restructure. For dental practices, confidence in data security also plays an 
important role. From their point of view, there is a great risk of data misuse concerning the practice data itself, but also for the patients' data. During the conversion from analog to digital, both in patient education and in areas of material ordering, all files must be kept twice.

A purely digital workflow management with a ticket system and digital inbox would be a welcome solution to simplify the various administrative and medical processes. This would give everyone involved in the process an overview of patient history and the current status of treatment at any time. In addition, everyone can quickly and easily get an overview of the upcoming administrative tasks.

\section{Interfaces in the healthcare system}

As mentioned above, dental practices have the most interfaces in the health care system with the state's $\mathrm{KZV}$, health insurance companies, and dental laboratories. Most interfaces to the health insurances exist via the KZV as an intermediary.

Practices send their invoices digitally via the KZV to the respective health insurer. The insurance pays the costs after a verification. The money is paid to the KZV, which forwards the money to the practice. As a result, this process is already fully digital. The exception is if the health insurance has queries during the billing verification. The clarification of the queries is done manually by mail.

Billing reports from each practice are sent collectively in PDF format via the KZV to one health insurance fund per federal state. Based on the PDF reports, the insurance company carries out the performance audits. In the future, performance audits could be completely digitalized.

The approval of dental prostheses by the health insurance fund is currently still done manually. Here, the treatment plans are sent by post either by the patient or the practice to the relevant health insurance company. Some health insurers digitize their incoming mail and process the plans internally digitally, but the original treatment plans still have to be approved and returned. Larger health insurers are working on digitizing the approval process by exchanging treatment plans digitally between practices and the health insurer in the future.

Consequently, dental practices, KZV, and health insurance companies have many interfaces that can be digitized. Here, a joint approach is necessary for a holistic transformation, as the various systems of the organizations must be compatible to achieve frictionless and secure digitization and automation. The focus here is primarily on the protection of personal health data as well as joint goal orientation. Through the TI, the legislature has provided a platform for the digital exchange of health data between the individual service providers. Simultaneously, health insurers and practices are striving to digitize process flows.

Here, a uniform approach is the best possible solution and, at the same time, the greatest challenge. The analysis of possible solutions for the joint transformation of the entire system can be the content of future research work.

\section{General interfaces}

In addition to the interfaces in the healthcare system, there are a large number of general interfaces that have a low level of digitization.

These include the interface to courts, tax offices, and tax consultants. The challenge here is to find the right approach between analog and digital and to be able to guarantee data completeness. In this case, many invoices, treatments data, and other data take months to retrieve and review. Finding a digital solution and sending the required files to the tax advisor is almost impossible. For this reason, a possible digital solution for the entire billing and court processes would be a huge. This includes all general areas and interfaces that are necessary to operate a business in Germany.

From the generated results of the interviews with dental practices, it is clear that these interfaces can in principle be easily digitized. However, the German judicial and tax systems are established systems that are similar in complexity to the healthcare system. Therefore, the digital transformation of these areas and interfaces is a holistic challenge that will take a long time. The basis here is that each dental practice is supported in this process and has clear contact persons.

In summary, it can be said that there are various starting points for increased and targeted digitization of administrative processes in dental practices. The possibilities presented for the respective factors stand for themselves as starting points. When analyzing and pursuing these, the dependencies on the other factors must be taken into account.

Dental practices hope to build a better relationship with their patients through digitization. This would lead to more transparency, targeted support of medical treatment and education, and thus to shorter treatment times and costs. 


\section{LIMITATIONS AND CONCLUSIONS}

This work focused on the German healthcare system and dentistry there. Therefore, no conclusions can be drawn for other countries or medical fields. The lack of a view from the perspective of patients, health insurers, the Association of Statutory Health Insurance Dentists, and the federal government represents an opportunity for further research.

In addition, a more detailed listing of all administrative processes in the practices would be useful to gain an even better insight into the daily work of medical staff in the dental field. For this, a larger number of participants would be important, as well as the exact elaboration of the individual roles and requirements. Our work can be a basis for further research in the field of digitalization and automation of processes in dentistry. The study of the processes and the problems of dental practices have given the first insight into this area and shows many approaches to optimize the processes. The development of a maturity model for process digitization in the healthcare system and specifically for dentists is required as a theoretical framework. Based on this theoretical background, further steps and scientific work could be derived.

To shape the future of a digital, targeted, and modern healthcare system, the points mentioned in the paper should be elaborated, deepened, and implemented. Digitalization is a topic that affects everyone and also has an impact on all areas of life. For this reason, dentistry must not be left out and digital and innovative solutions should be developed for this area in the future.

\section{REFERENCES}

Ahmed, E. S., Ahmad, M. N., \& Othman, S. H. (2019). Business process improvement methods in healthcare: a comparative study. International Journal of Health Care Quality Assurance, 32(5), 887-908. https://doi.org/10.1108/IJHCQA-07-2017-0116

Andreasson, J., Eriksson, A., \& Dellve, L. (2016). Health care managers' views on and approaches to implementing models for improving care processes. Journal of Nursing Management, 24(2), $219-227$. https://doi.org/10.1111/jonm.12303

Aufgaben und Organisation der GKV|BMG. (2018). https://www.bundesgesundheitsministerium.de/themen/krankenversicherung/grundprinzipien/aufgaben-undorganisation-der-gkv.html

Baldassarre, F., \& Ricciardi, F. (2016). Business process management to manage clinical risk: a case study in the healthcare sector. Conference" Excellence in ..., September, $37-50$. http://www.toulonveronaconf.eu/papers/index.php/tvc/article/view/400

Barriball, L., \& While, A. (1994). Collecting data using a semi-structured interview: a discussion paper. In Journal of Advanced Nursing (Vol. 19).

Buttigieg, S., Dey, P. K., \& Gauci, D. (2016). Business process management in health care: current challenges and future prospects. Innovation and Entrepreneurship in Health, January, 1. https://doi.org/10.2147/ieh.s68183

Cherni, J., Martinho, R., \& Ghannouchi, S. A. (2019). Towards Improving Business Processes based on preconfigured KPI target values, Process Mining and Redesign Patterns. Procedia Computer Science, 164, $279-284$. https://doi.org/10.1016/j.procs.2019.12.184

de Koning, H., Verver, J. P. S., van den Heuvel, J., Bisgaard, S., \& Does, R. J. M. M. (2006). Lean six sigma in healthcare. Journal for Healthcare Quality: Official Publication of the National Association for Healthcare Quality, 28(2), 4-11. https://doi.org/10.1111/j.1945-1474.2006.tb00596.x

De Mast, J., Kemper, B., Does, R. J. M. M., Mandjes, M., \& Van Der Bijl, Y. (2011). Process improvement in healthcare: Overall resource efficiency. Quality and Reliability Engineering International, 27(8), 1095-1106. https://doi.org/10.1002/qre.1198

De Ramón Fernández, A., Ruiz Fernández, D., \& Sabuco García, Y. (2019). Business Process Management for optimizing clinical processes: A systematic literature review. Health Informatics Journal. https://doi.org/10.1177/1460458219877092

E-Health - Digitalisierung im Gesundheitswesen. (2020). https://www.bundesgesundheitsministerium.de/e-healthinitiative.html

El Hadj Amor, E. A., \& Ghannouchi, S. A. (2017). Towards KPI-Based Health Care Process Improvement. Procedia Computer Science, 121, 767-774. https://doi.org/10.1016/j.procs.2017.11.099

Fältholm, Y., \& Jansson, A. (2008). The implementation of process orientation at a Swedish hospital. The International Journal of Health Planning and Management, 23(3), 219-233. https://doi.org/10.1002/hpm.884

Flick, U., von Kardorff, E., \& Steinke, I. (2004). Wolff in Flick et a . July, 178-183. https://www.researchgate.net/profile/Stephan_Wolff2/publication/305496229_Wolff_in_Flick_et_a/links/579204600 $8 \mathrm{aec} 89 \mathrm{db} 77 \mathrm{fca} \mathrm{c} /$ Wolff-in-Flick-et-a.pdf\#page $=268$

Gesundheitswesen in Deutschland. (n.d.). Retrieved August 10, 2020, from https://vbw-zukunftsrat.de/Gesundheit-undMedizin/Analyse?box=56\&box_56=Gesundheitswesen-in-Deutschland 
Goreva, N., Mishra, S., Draus, P., \& Caputo, D. (n.d.). Impacts of Organizational Structure and Business Processes on Effective Security Governance in Healthcare Organizations. 1-12. http://proxy1.ncu.edu/login?url=http://search.ebscohost.com/login.aspx?direct=true \&db=bth\&AN=116211858\&site= eds-live

Hellström, A., Lifvergren, S., \& Quist, J. (2010). Process management in healthcare: Investigating why it's easier said than done. Journal of Manufacturing Technology Management, 21(4), $499-511$. https://doi.org/10.1108/17410381011046607

Ilahi, L., Ghannouchi, S. A., \& Martinho, R. (2014). Healthcare information systems promotion: From an improved management of telemedicine processes to home healthcare processes. ACM International Conference Proceeding Series, June 2016, 333-338. https://doi.org/10.1145/2669711.2669920

Khodambashi, S. (2013). Business Process Re-engineering Application in Healthcare in a Relation to Health Information Systems. Procedia Technology, 9(2212), 949-957. https://doi.org/10.1016/j.protcy.2013.12.106

KZBV - Kassenzahnärztliche Bundesvereinigung - Startseite. (n.d.). Retrieved August 8, 2020, from https://www.kzbv.de/

Lenz, R., \& Reichert, M. (2007). IT support for healthcare processes - premises, challenges, perspectives. Data and Knowledge Engineering, 61(1), 39-58. https://doi.org/10.1016/j.datak.2006.04.007

Liu, C., Xiong, H., Papadimitriou, S., Ge, Y., \& Xiao, K. (2017). A Proactive Workflow Model for Healthcare Operation and Management. IEEE Transactions on Knowledge and Data Engineering, 29(3), 586-598. https://doi.org/10.1109/TKDE.2016.2631537

Maier, C., \& Juschkat, T. (2020). Digitization in the German Health Care System - An Analysis of the Status Quo Using the Example of the Dental Sector. European Journal of Business and Management Research, 5(3). https://doi.org/10.24018/ejbmr.2020.5.3.331

Marsilio, M., \& Prenestini, A. (2020). Making it happen: Challenges and transformations in health care processes, people management, and decision-making. Health Services Management Research, 33(2), 53-54. https://doi.org/10.1177/0951484820906314

Martinho, R., Rijo, R., \& Nunes, A. (2015). Complexity Analysis of a Business Process Automation: Case Study on a Healthcare Organization. Procedia Computer Science, 64, 1226-1231. https://doi.org/10.1016/j.procs.2015.08.510

McIntosh, M. J., \& Morse, J. M. (2015). Situating and constructing diversity in semi-structured interviews. Global Qualitative Nursing Research, 2. https://doi.org/10.1177/2333393615597674

Mens, J., Ahlers, B., van Hattem, B., \& Ravesteyn, P. (2015). Value-Based Healthcare Through a Standardised Process Management Model. ECMLG 2015 Proceedings, 8.

Müller, R., \& Rogge-Solti, A. (2011). BPMN for Healthcare Processes. In undefined. http://spz.charite.de

Plsek, P. E. (1997). Systematic design of healthcare processes. Quality and Safety in Health Care, 6(1), 40-48. https://doi.org/10.1136/qshc.6.1.40

Reichert, M. (2011). What BPM technology can do for healthcare process support. Lecture Notes in Computer Science (Including Subseries Lecture Notes in Artificial Intelligence and Lecture Notes in Bioinformatics), 6747 LNAI, 2-13. https://doi.org/10.1007/978-3-642-22218-4_2

Rolón, E., Chavira, G., Orozco, J., \& Soto, J. P. (2015). Towards a Framework for Evaluating Usability of Business Process Models with BPMN in Health Sector. Procedia Manufacturing, 3(February 2016), 5603-5610. https://doi.org/10.1016/j.promfg.2015.07.748

Ruiz, F., Garcia, F., Calahorra, L., Llorente, C., Gonçalves, L., Daniel, C., \& Blobel, B. (2012). Business process modeling in healthcare. Studies in Health Technology and Informatics, 179(May 2014), $75-87$. https://doi.org/10.3233/978-1-61499-086-4-75

Startseite: Bundeszahnärztekammer - Arbeitsgemeinschaft der Deutschen Zahnärztekammern e.V. (BZÄK). (n.d.). Retrieved August 8, 2020, from https://www.bzaek.de/

Stephenson, C., \& Bandara, W. (2007). Enhancing best practice in public health: Using process patterns for business process management. Proceedings of the 15th European Conference on Information Systems, ECIS 2007, 2007, 2123-2134.

Telematikinfrastruktur. (n.d.). Retrieved August 10, 2020, from https://www.gematik.de/telematikinfrastruktur/

Vest, J. R., \& Gamm, L. D. (2009). A critical review of the research literature on Six Sigma, Lean and StuderGroup's Hardwiring Excellence in the United States: The need to demonstrate and communicate the effectiveness of transformation strategies in healthcare. Implementation Science, 4(1), 1-9. https://doi.org/10.1186/1748-5908-4-35

Vom Brocke, J., Simons, A., Niehaves, B., Riemer, K., Plattfaut, R., \& Cleven, A. (2009). Reconstructing the giant: On the importance of rigour in documenting the literature search process. 17th European Conference on Information Systems, ECIS 2009.

Was macht ein angestellter Zahnarzt? (2018). https://www.deutscher-zahnarzt-service.de/blog/was-macht-einangestellter-zahnarzt

Webster, J., \& Watson, R. T. (2002). Analyzing the past to prepare for the future: Writing a literature review Reproduced with permission of the copyright owner . Further reproduction prohibited without permission . MIS Quarterly, 26(2), xiii-xxiii. https://doi.org/10.2307/4132319 